\title{
New Type IV Pili-Related Genes Involved in Early Stages of Ralstonia solanacearum Potato Infection
}

\author{
María Inés Siri, ${ }^{1}$ Analía Sanabria, ${ }^{1}$ Christian Boucher, ${ }^{2}$ and María Julia Pianzzola ${ }^{1}$ \\ ${ }^{1}$ Cátedra de Microbiología, Departamento de Biociencias, Facultad de Química, Universidad de la República, Av. Gral. Flores \\ 2124, CP11800, Montevideo, Uruguay; ${ }^{2}$ Laboratoire des Interactions Plantes Micro-organismes (LIPM), UMR CNRS-INRA \\ 2594/441, F-31320 Castanet Tolosan, France
}

Submitted 30 July 2013. Accepted 19 February 2014.

\begin{abstract}
This study provides insights into the pathogenesis of Ralstonia solanacearum, in particular with regards to strains belonging to phylotype IIB, sequevar 1 (IIB-1) and their interaction with potato, its natural host. We performed a comparative genomic analysis among IIB-1 $R$. solanacearum strains with different levels of virulence in order to identify candidate virulence genes. With this approach, we identified a 33.7-kb deletion in a strain showing reduced virulence on potato. This region contains a cluster of six genes putatively involved in type IV pili (Tfp) biogenesis. Functional analysis suggests that these proteins contribute to several Tfp-related functions such as twitching motility and biofilm formation. In addition, this genetic cluster was found to contribute to early bacterial wilt pathogenesis and colonization fitness of potato roots.
\end{abstract}

Ralstonia solanacearum is a gram-negative, soilborne $\beta$ proteobacterium that causes bacterial wilt, one of the most devastating plant diseases in the world. The high importance of this organism results from its global distribution and its wide host range affecting more than 200 plant species, including important food crops such as potato, tomato, eggplant, and banana (Elphinstone 2005; Hayward 1994b). R. solanacearum is a highly diversified pathogen, with exceptional diversity among strains regarding host range, geographical distribution, pathogenicity, epidemiological relationships, and physiological properties (Buddenhagen et al. 1962; Castillo and Greenberg 2007; Hayward 1991, 1994a). Actually, it is considered a species complex: a heterogeneous group of related strains which are distributed in four lineages termed phylotypes, defined as monophyletic clusters of strains revealed using phylogenetic analysis of sequence data (Fegan and Prior 2005).

Bacterial wilt of potato, also known as potato brown rot, is mainly caused by one subgroup of the $R$. solanacearum species complex classified as phylotype IIB, sequevar 1 (IIB-1). The disease is among the most serious constraints for potato production under tropical and subtropical conditions, causing extensive damage and significant economic losses worldwide (Elphinstone 2005). Control of the disease is especially hampered because IIB-1 $R$. solanacearum strains have the ability

Corresponding author: M. I. Siri; Telephone: +598-2-9244209; Fax: +5982-9241906; E-mail: msiri@fq.edu.uy

* The $\boldsymbol{e}$-Xtra logo stands for "electronic extra" and indicates that three supplementary tables and one supplementary figure are published online.

(C) 2014 The American Phytopathological Society to cause symptomless or latent infections that facilitate the dissemination of the pathogen through seed potato tubers or plant cuttings (Janse 1996; Swanson et al. 2005).

In the natural infection process, $R$. solanacearum invades plants via wounds or secondary root emergence points and propagates to the root cortex and then to the vascular system (Vasse et al. 1995). After the bacterium reaches the xylem vessels, the infection becomes systemic, with further bacterial multiplication and the production of large amounts of extracellular polysaccharides which obstruct vascular bundles, therefore leading to complete wilting and plant death (Buddenhagen and Kelman 1964). The bacterium then returns to the soil, where it can be associated with plant debris and weed rhizospheres and survive under humid conditions for a long time (Coutinho 2005).

A large set of specialized gene products is required to accomplish tasks at different steps of the infection process. Virulence factors, in addition to exopolysaccharide production, include various plant cell-wall-degrading enzymes and a plethora of effector proteins translocated into the plant cell through the type III secretion system (T3SS) (Genin and Boucher 2004; Schell 2000). Bacterial motility, including both flagellar swimming motility and twitching motility mediated by type IV pili (Tfp), also contribute to virulence (Liu et al. 2001; Tans-Kersten et al. 2001). However, our knowledge on the complex and highly coordinated pathogenesis process is far from sufficient. In addition, to date, most of the studies regarding virulence traits of $R$. solanacearum focused on the interaction with tomato as natural host and Arabidopsis as a model host, while other important susceptible crops such as potato remain to be further explored (Genin and Denny 2012).

Genome sequencing has led to the development of highthroughput approaches to define essentiality of genes on a genomic scale, gathering a large amount of information on plant-microbe interactions. With the availability of genome sequences of representative $R$. solanacearum strains, new pathogenicity determinants have been identified by systematic screenings using different approaches such as in vivo expression technology, microarray transcriptome analysis, transposon insertion mutagenesis, and bioinformatics genomic comparisons (Brown and Allen 2004; Gabriel et al. 2006; González et al. 2011; Lin et al. 2008; Occhialini et al. 2005). Comparative genomic hybridization (CGH) using microarray technology provides another alternative to explore the genetic diversity within any particular group of bacteria and to identify virulence factors and genes involved in environmental persistence of pathogens. The goal is to correlate these differences to biological functions and to gain insight into selective evolutionary pressures and patterns of gene transfers or losses, particularly 
within the context of virulence in pathogenic species. A pangenome microarray of $R$. solanacearum covering the gene repertoire of three strains (GMI1000, IPO1609, and Molk2) was developed and applied in a $\mathrm{CGH}$ approach, broadening our knowledge of the evolution and taxonomy of the $R$. solanacearum species complex (Guidot et al. 2007, 2009b; Remenant et al. 2010).

In a previous work, we found differences in virulence among several $R$. solanacearum strains isolated from potato crops in Uruguay (Siri et al. 2011). In order to gain insight into the genetic basis underlying these phenotypes, a CGH-microarray analysis was conducted and candidate pathogenicity genes were identified by selecting specific genes from strains with different virulence levels. With this approach we identified a genetic cluster putatively involved in Tfp biogenesis. We provided experimental evidence suggesting that the proteins codified by these genes have a contribution to the early bacterial wilt pathogenesis on potato by improving colonization fitness on potato roots.

\section{RESULTS}

\section{Identification and validation}

of candidate pathogenicity genes in $R$. solanacearum.

$\mathrm{CGH}$ analysis on a spotted microarray reflecting the pangenome of $R$. solanacearum was performed to compare the gene content of a set of strains isolated in Uruguay exhibiting different virulence levels to identify candidate pathogenicity genes. To support the microarray result, we performed the polymerase chain reaction (PCR) amplification of one genomic fragment for each candidate gene.

A genomic comparison was performed in order to identify specific differences in gene content of strain UY043 (Supplementary Table S1). This strain displayed low virulence on several hosts and was isolated from soil, whereas the other $R$. solanacearum strains were isolated from potato tubers with typical bacterial wilt symptoms (Siri et al. 2011). Therefore, we focused the analysis on identifying any genomic changes incurred in a strain isolated from the environment, which may explain the low virulence. By comparison with the strain IPO1609 draft genome, it was noticed that 25 genes absent in strain UY043 were found to localize to one single genomic region of $33.7 \mathrm{~kb}$ in size. Validation by PCR amplification confirmed that all 25 genes that constitute this region were absent in strain UY043 and present in $12 R$. solanacearum strains from Uruguay, as well as in reference strain IPO1609. In addition, five additional candidate genes were identified outside this region but only two (RSIPO_03704 and RSIPO_03609) were confirmed by PCR as exclusively present in strain UY043.

Description of the deleted region in strain UY043 (DR43).

Because most of the identified candidate genes share the same location within the genome, we decided to concentrate our research on this region, named DR43. Based on information from strain IPO1609 draft genome, DR43 comprises

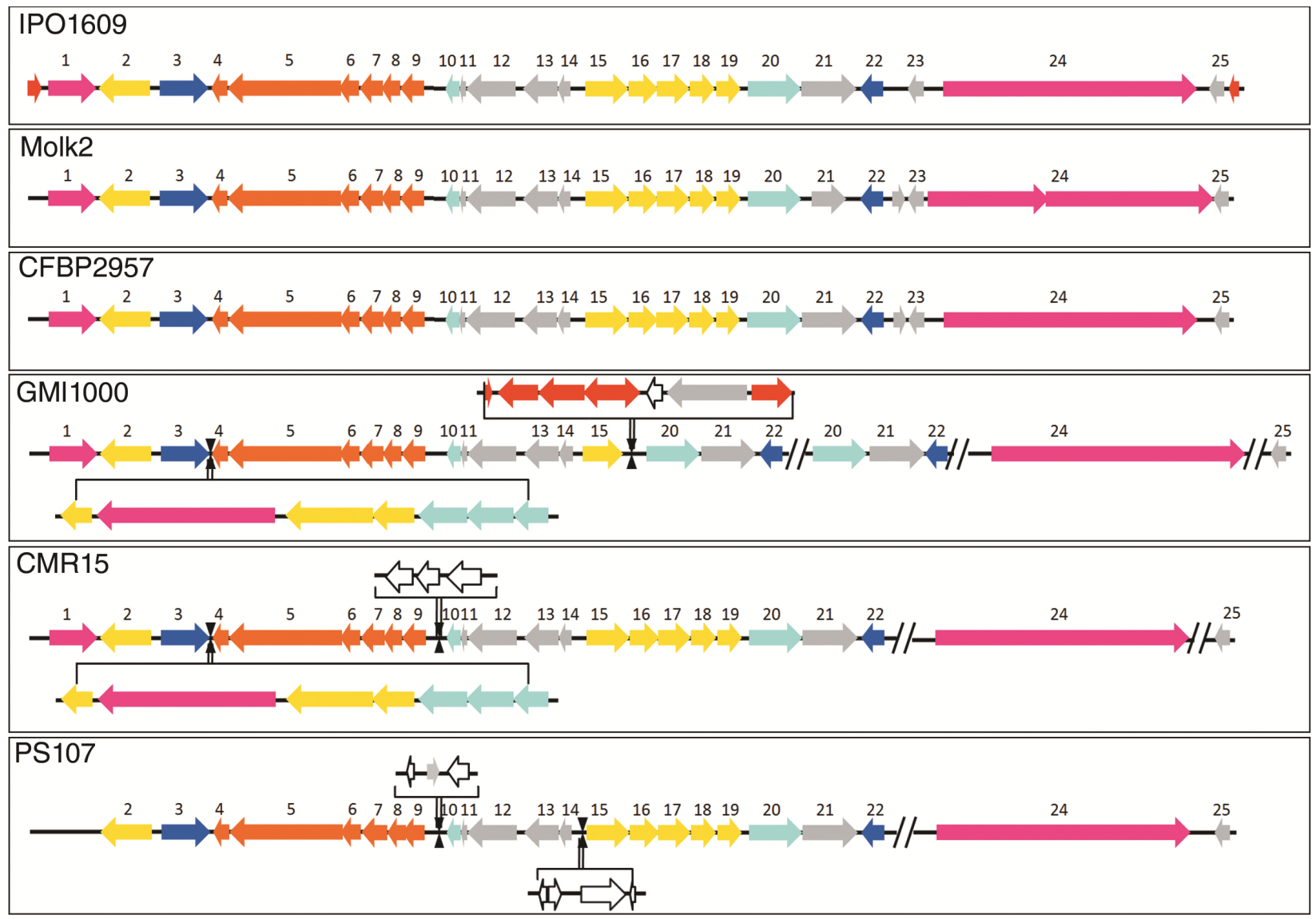

Fig. 1. Comparison of region DR43 across Ralstonia solanacearum-sequenced strains belonging to different phylotypes: IPO1609 (IIB-1), Molk2 (IIB-3), CFBP2957 (IIA-36), GMI100 (I-18), CMR15 (III-29), and PS107 (IV-10). Numbers above arrows indicate open reading frame number, and color code represents different gene classes according the $R$. solanacearum genome database from LIPM-INRA, Toulouse. Color codes: dark blue $=$ small molecule metabolism; light blue $=$ central intermediary metabolism; orange $=$ structural elements; yellow $=$ cell processes; red $=$ elements of external origin; pink $=$ miscellaneous (virulence); gray $=$ hypothetical protein; no color $=$ unknown. For strains GMI1000, CMR15, and PS107, additional genes not present in strain IPO1609 were added above or below the central map. 
25 genes covering $33.7 \mathrm{~kb}$ (Supplementary Fig. S1). The entire region possess an average $\mathrm{G}+\mathrm{C}$ content of $66.7 \%$, equal to the average $\mathrm{G}+\mathrm{C}$ content of the complete genome. Interestingly, it was found that, in strain IPO1609, this region is flanked by two 480-bp direct repeat sequences sharing high homology (98.3\%), suggesting that the deletion in strain UY043 may have proceeded through recombination at these loci. Analysis of the strain UW551 draft genome database (Contig05764, position 42,531 to 77,542 ), revealed almost complete identity with strain IPO1609 with respect to the 25 genes present on DR43, although the length of genes that had been annotated was somewhat different.

According to the annotation for strain IPO1609, the region contained 25 open reading frames (ORF) that putatively encode: i) two proteins directly involved in virulence identified as protein effectors secreted through the T3SS (ORF1 and ORF24; RSIPO_04287 and RSIPO_04310), ii) a cluster of six genes related to the biogenesis of Tfp (ORF 4 to 9; RSIPO_04290 to RSIPO_04295), iii) a cluster of five proteins involved in amino acid transport (ORF 15 to 19; RSIPO_04301 to RSIPO_ 04305), iv) a multidrug transport protein (ORF 2; RSIPO_ 04288), v) two proteins involved in biosynthesis of spermidine (ORF 10 and ORF 20; RSIPO_04296 and RSIPO_4306), vi) two proteins related to the metabolism of small molecules (ORF 3 and ORF 22; RSIPO_04289 and RSIPO_04308), and vii) seven proteins with unknown function.

To allow a cross-comparison of the identified genomic region among other $R$. solanacearum strains belonging to different phylotypes, we searched for the corresponding homologous proteins in five additional sequenced strains (Fig. 1; Supplementary Table S2). This comparison led us to identify that the region DR43 is, in fact, located within the megaplasmid. High conservation was found between strains belonging to the phylotype II because, for Molk2 and CFBP2957, all 25 ORF were clustered in the same order, sharing homology with the same genes in strain IPO1609. In strains belonging to other phylotypes, a greater degree of variation was observed. Some genes were absent or additional genes were found interspersed be-
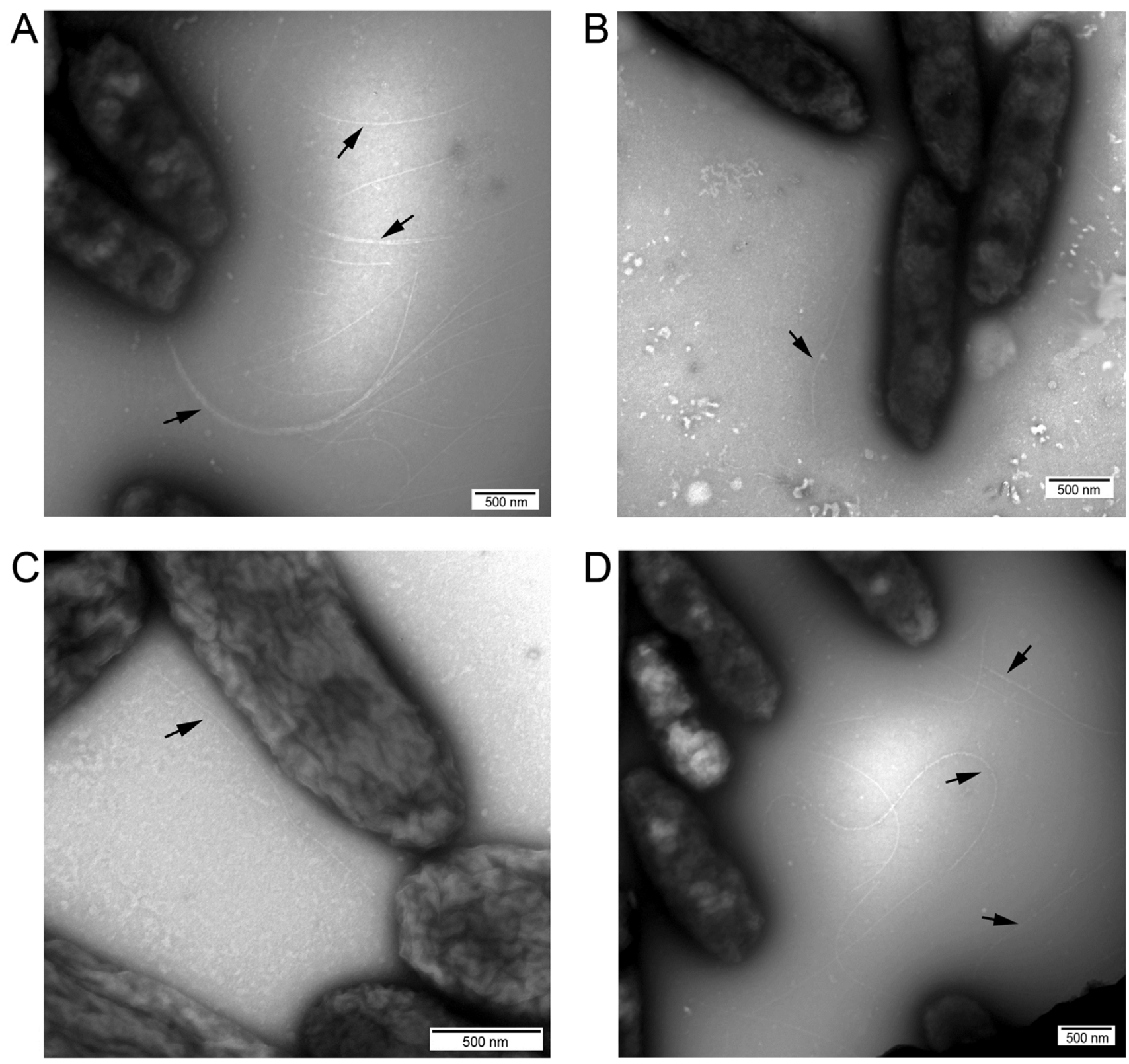

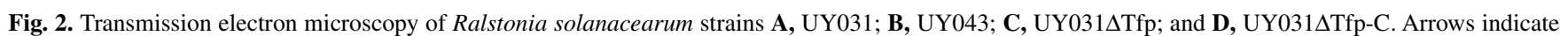
type IV pili. 
tween the ORF identified in IPO1609. For instance, the corresponding region in strain GMI1000 showed a group of eight additional conserved genes located between ORF 3 and ORF 4 and completely lacked ORF 16 to 19 as well as ORF 23, which also were not present elsewhere in the genome. Instead, this region in strain GMI1000 is interrupted by insertion sequence elements and transposons as well as a region with alternative codon usage (ACUR), suggesting the occurrence of a genome rearrangement within this region during evolution.

\section{Function analysis of candidate genes.}

Annotation data for genes located in the DR43 region from strain IPO1609 revealed several ORF that might be related to virulence traits. In this study, we focused the analysis on a genetic cluster putatively involved in Tfp biogenesis: genes RSIPO_04290 to RSIPO_04295 (ORF 4 to 9). In order to assess the biological role of these six genes, we first tried to complement strain UY043 with a plasmid containing this genetic cluster. Unfortunately, we failed to obtain any complementant clone, even after several trials using different conditions for transformation (data not shown). Using a different approach, a mutant strain named UY031 $\Delta$ Tfp was constructed in the background of the highly aggressive strain UY031, in which the six Tfp-related genes were deleted and replaced by a spectinomycin-resistance cassette. Mutant strain UY031 $\Delta$ Tfp, as well as strain UY043, showed a normal mucoid colony morphology when grown on casamino acid peptone glucose (CPG) and also behaved as its wild-type parent in terms of growth rate in both rich medium (CPG) and minimal medium (MM) (data not shown). To complete the functional analysis, strain UY031 1 Tfp was complemented by introduction of plasmid pLAFR6-Tfp43, which harbors an insert covering the six deleted Tfp-related genes, generating strain UY031 $\Delta$ Tfp-C.

\section{ORF 4 to 9 are involved}

\section{in Tfp abundance and functionality.}

The wild-type and mutant $R$. solanacearum strains were subsequently examined for the presence of Tfp by transmission electron microcopy (TEM). All strains showed long and thin filaments denoted as Tfp, suggesting that ORF 4 to 9 are dispensable for the biogenesis of Tfp in R. solanacearum (Fig. 2 ). However, although we did not perform a quantitative analysis, we noted that the wild-type strain UY031 exhibited multiple filaments per cell and a higher proportion of piliated cells than strains UY043 and UY031 0 Tfp. In addition, for strain UY031, bundles formed by the junction of numerous pili were observed frequently. Complementation of the mutant strain with the corresponding genes expressed in trans restored the wild-type phenotype of strain UY031.

To determine whether this genetic cluster is involved in Tfp function, we compared the $R$. solanacearum strains for activities known to be mediated by Tfp (i.e., twitching motility and biofilm formation). To assess twitching motility, the bacterial colonies on CPG agar were compared under a light micro-
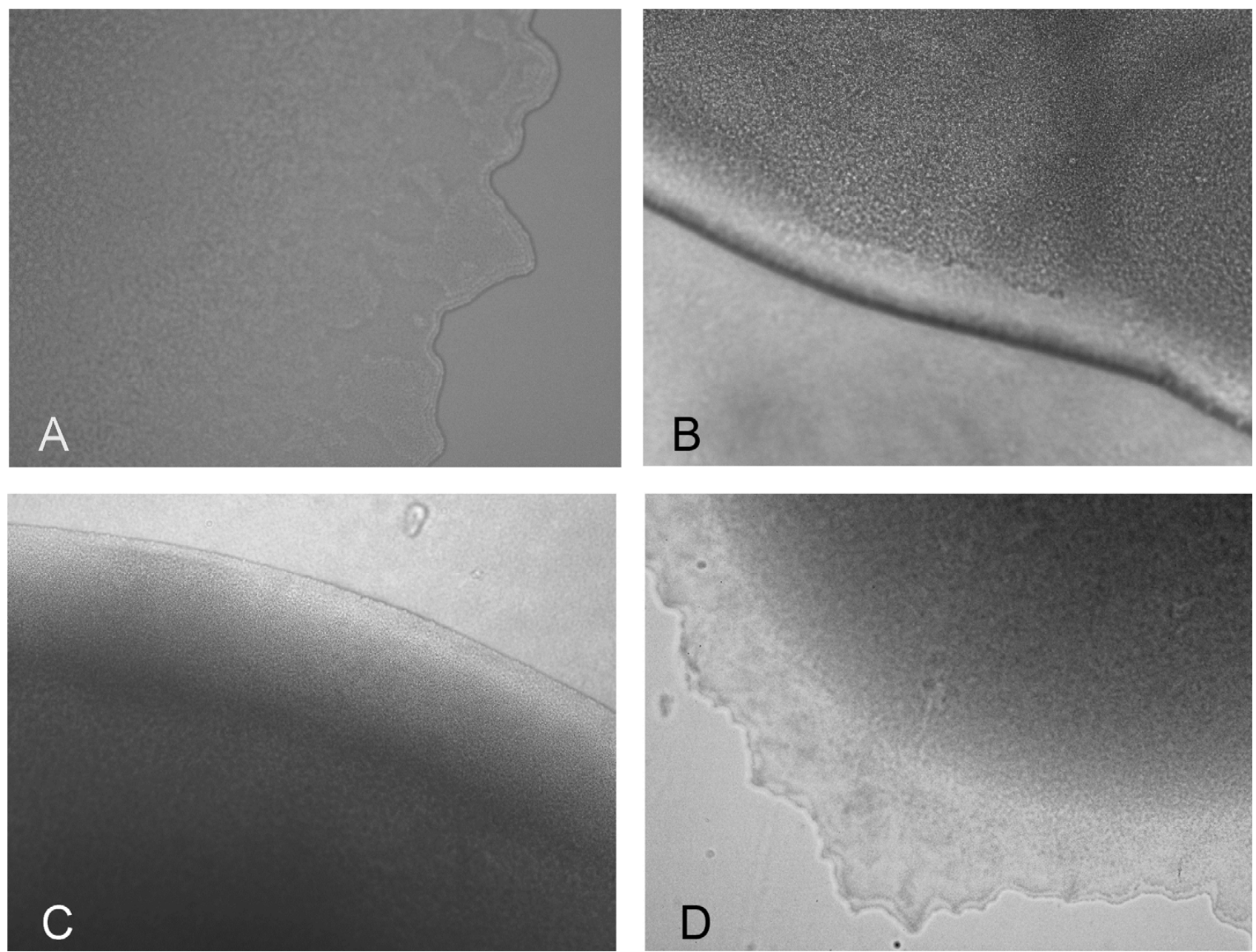

Fig. 3. Twitching motility assay for of Ralstonia solanacearum strains A, UY031; B, UY043; C, UY031 $\Delta$ Tfp; and D, UY031 $\Delta$ Tfp-C as seen through light microscopy after $48 \mathrm{~h}$ of growth on casamino acid peptone glucose plates. Typical colonies with multiple irregular projections are formed by bacteria migrating via twitching. 
scope (Fig. 3). Typical colonies with layered edges and multiple irregular projections were observed for wild-type strain UY031 and the complemented strain UY031 1 Tfp, indicating the presence of bacteria migrating via twitching. In contrast, both strains UY043 and UY031 1 Tfp formed colonies with smooth margins, suggesting that deletion of this genetic cluster affected the ability to migrate via twitching motility in culture.

Biofilm formation for wild-type and mutant $R$. solanacearum strains was assessed by a quantitative microtiter plate assay (Fig. 4). Interestingly, the wild-type strain UY031 formed significantly more biofilm than strains UY043 and UY031 1 Tfp while the complemented strain UY031 $\Delta$ Tfp nearly restored the levels of biofilm formation of wild-type strain UY031 $(P=0.2530)$.

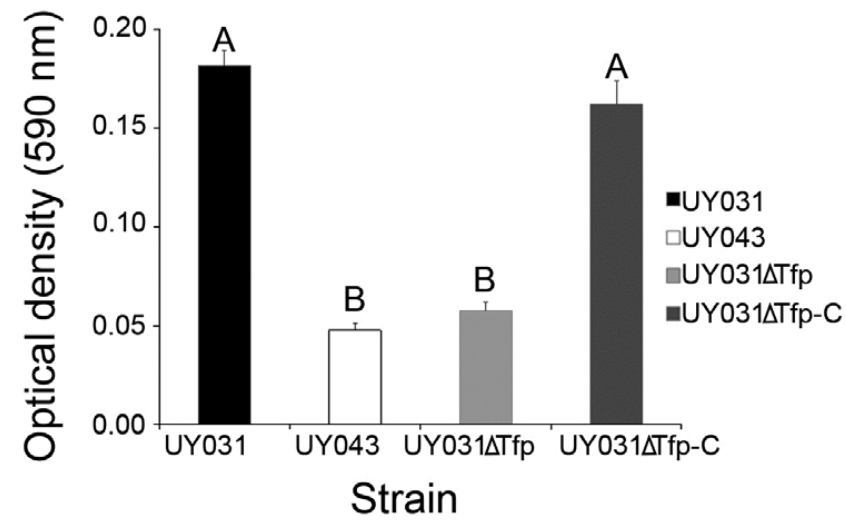

Fig. 4. Biofilm formation by Ralstonia solanacearum wild-type strains UY031 and UY043, mutant strain UY031 $\Delta$ Tfp, and the complementant strain UY031 $\Delta \mathrm{Tfp}-\mathrm{C}$. Biofilm formation was quantified by crystal violet staining and measuring the optical density at $590 \mathrm{~nm}$. Data represent the mean of three independent experiments with eight replicates each and the error bars represent the standard error of the means. Different letters indicate significant differences among strains (Tukey's multiple comparison test, $P=0.05$ ).
Tfp-related genes are important for full pathogenicity on potato.

To determine the role of Tfp-related genes in pathogenesis, we compared the virulence of strains UY031 and UY031 1 Tfp following inoculation of potato plants using two different procedures: soil and direct petiole inoculation (Fig. 5; Supplementary Table S3). When bacteria were directly introduced into host vascular tissue, no significant differences were observed among disease progress curves of wild-type and mutant strains $(P=$ 0.2438) (Fig. 5A). Potato plants began to develop wilt symptoms 4 days after inoculation (DAI), and almost all were completely dead after 12 days. In contrast, using a soil inoculation assay, which requires bacteria to locate and invade host roots from soil, significant differences were observed among the disease progress curves of the strains $(P<0.0001)$ (Fig. 5B). Mutant strain UY031 $\Delta$ Tfp exhibited reduced virulence in comparison with wild-type strain UY031, indicating that deleted genes are required for full pathogenicity on potato. Nevertheless, strain UY043 was even less virulent than UY031 $\Delta$ Tfp, suggesting that additional pathogenicity determinants may explain the differences between these strains. Notably, for both UY031 $\Delta$ Tfp and UY043 strains, appearance of symptoms was delayed and leaf wilting was observed only after 9 days whereas, for strain UY031, first symptoms appeared 5 DAI (Fig. 5B). When tested by the soil inoculation procedure, the complemented mutant named UY031 $\Delta$ Tfp-C restored the virulence of the resulting strain to a level which was statistically indistinguishable from the wild-type strain UY031 (Fig. 5B). Overall, these results confirm the biological role of this cluster of Tfp-related genes in virulence of $R$. solanacearum toward potato.

\section{Tfp-related genes contribute}

\section{to colonization fitness of potato roots.}

Because mutant strain UY031 $\mathrm{Tfp}$ displayed a delayed wilting response in comparison with wild-type strain UY031, we were interested to know whether this cluster of Tfp-related
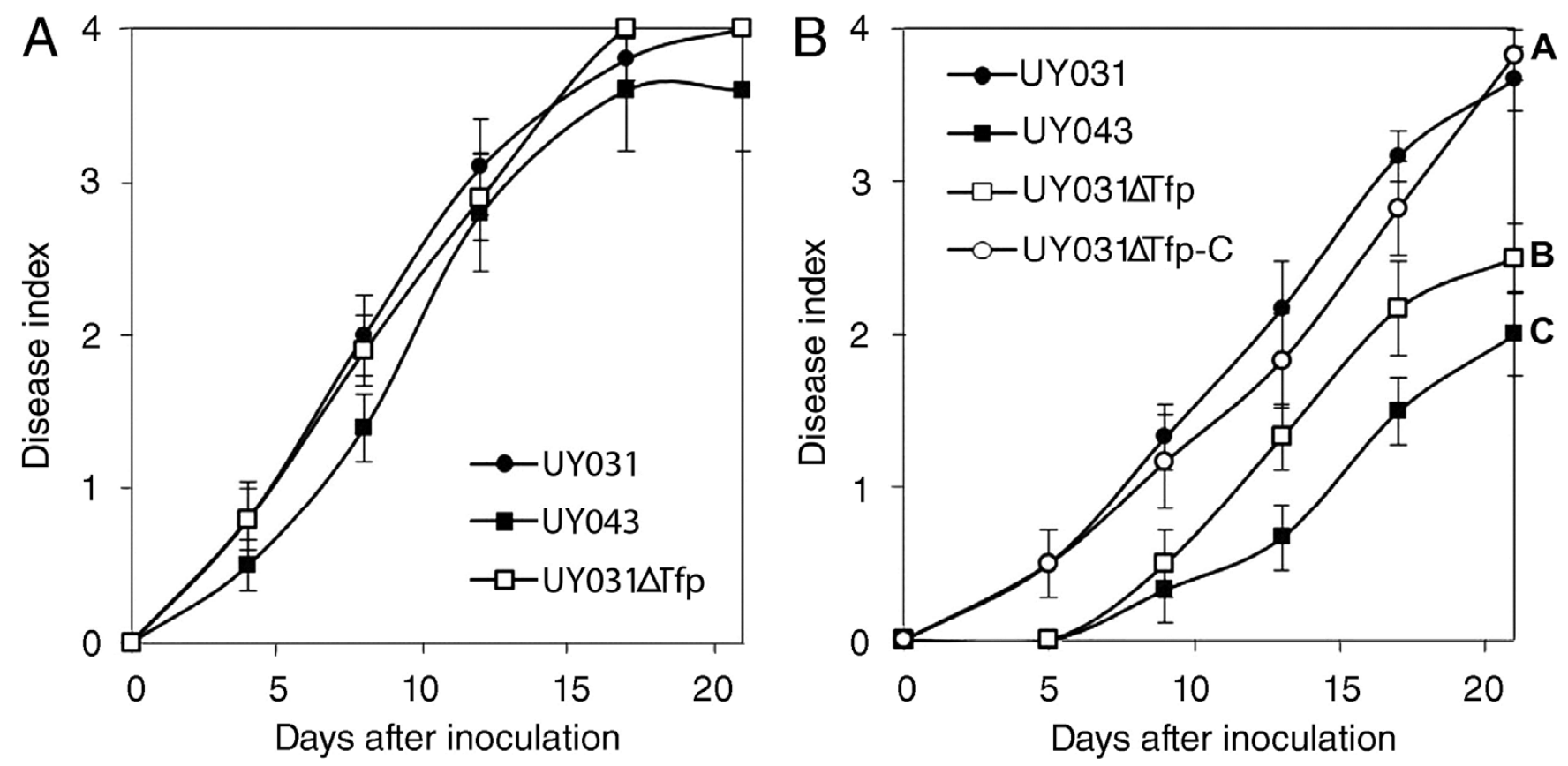

Fig. 5. Disease progress curves of Ralstonia solanacearum strains on potato ('Chieftain'). Wild-type strains UY031 (black circles) and UY043 (black squares), mutant strain UY031 $\Delta$ Tfp (white squares), and the complemented strain UY031 $\Delta$ Tfp-C (white circles) were tested by A, direct petiole inoculation and $\mathbf{B}$, soil inoculation. Disease development was recorded for 21 days at regular time intervals on a disease index scale of 0 to 4 . Each point represents the mean disease index for two independent experiments with a total of six and twelve replicates for soil inoculation and direct petiole inoculation, respectively. Bars represent standard error of the mean. Different letters indicate significant differences among strains according to the Tukey's multiple comparison test $(P=0.05)$. 
genes is involved in the first stages of infection. For that purpose, an in vitro root inoculation assay was carried out to evaluate the ability of $R$. solanacearum strains to invade the roots and colonize potato plants. The standardized and reproducible conditions achieved by this assay facilitate the comparison of bacterial densities in plant tissues (Vailleau et al. 2007). In vitro plantlets growing in vertically oriented, squared petri dishes were inoculated by applying the bacterial suspension along the entire length of the roots. Population dynamics of each strain was evaluated by determining the internal bacterial densities in roots and stems sections at different sampling times by dilution plating (Fig. 6).

At 1 DAI, the pathogen was only found in roots and there were no significant differences between population densities of wild-type and mutant strains $(P=0.4670)$ (Fig. 6B). Plants inoculated with strain UY031 showed a rapid increase in bacte- rial densities, in agreement with the high virulence observed previously for this strain. Bacterial measurements 4 DAI revealed a significant reduction in the colonization ability of strain UY043 and UY031 $\Delta$ Tfp, reaching a population approximately 50 -fold lower than strain UY031 for both root $(P=0.003)$ and stem $(P=0.0015)$ tissues (Fig. 6C). The internal bacterial densities at 7 DAI showed a correlation with virulence of strains measured by wilting scoring using the soil inoculation procedure, where mutant strain UY031 $\Delta$ Tfp exhibited an intermediate response between strain UY031 and UY043. In stem tissue at 7 DAI, differences in bacterial populations were more pronounced and significant reductions of 200-fold for strain UY031 $\Delta$ Tfp and 2,500-fold for UY043 were detected in comparison with strain UY031 $(P=0.0001)$ (Fig. 6D). In root tissue, strain UY043 reached a population approximately 50-fold lower than strain UY031 $(P=0.0045)$. Strain UY031 $P$ Tfp
A
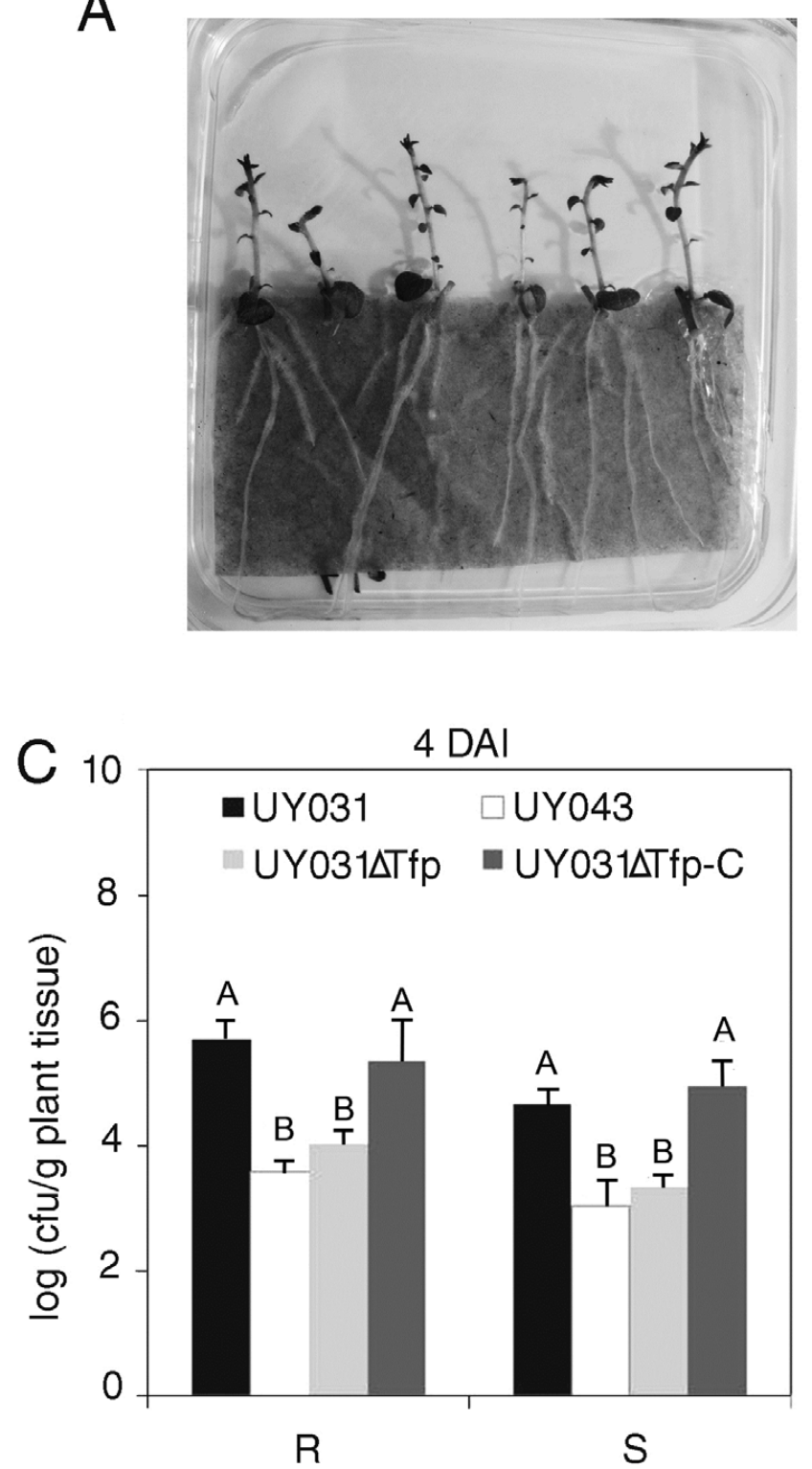
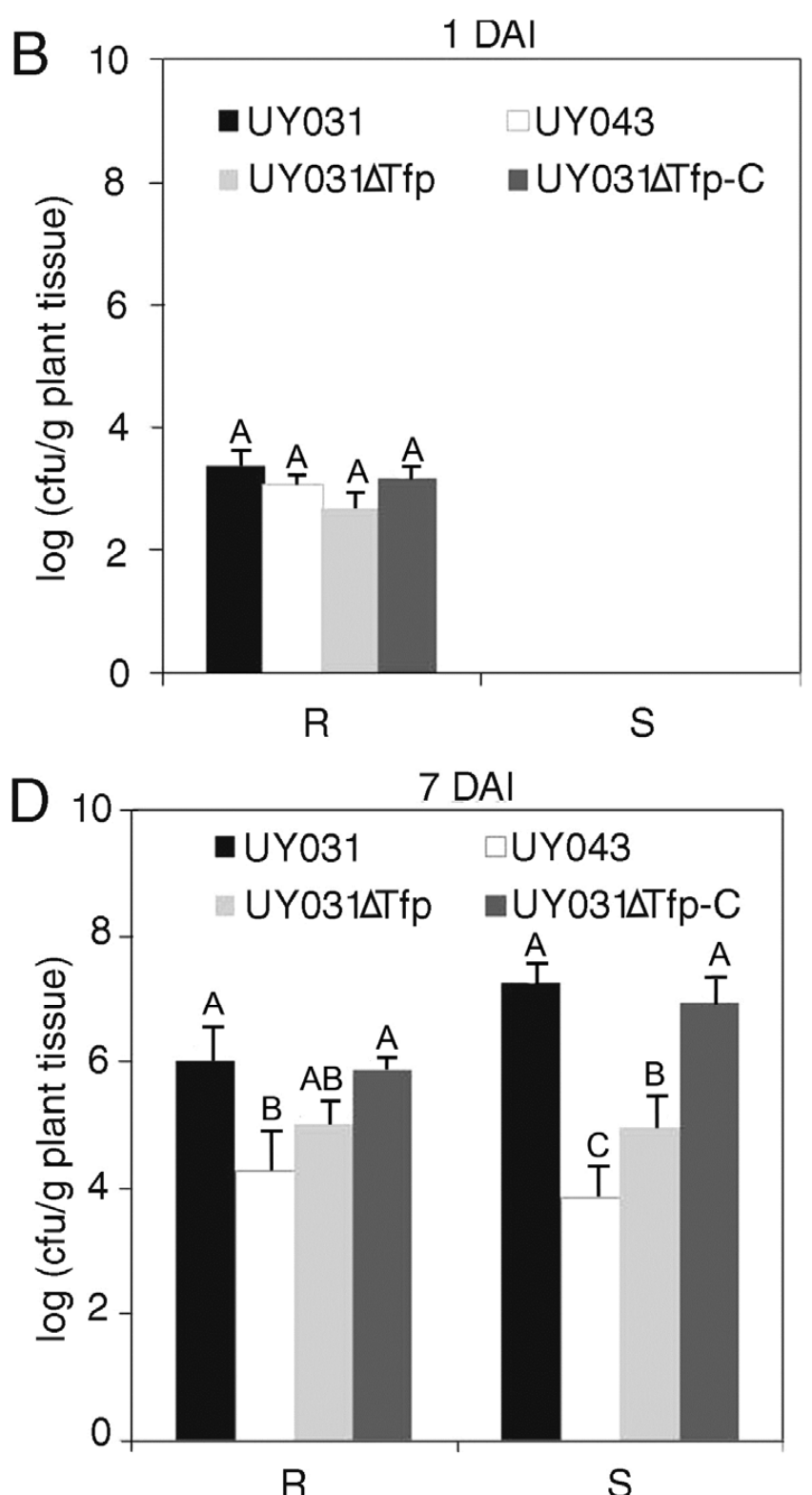

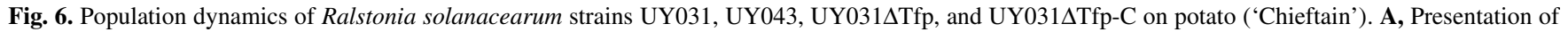
the system used for the in vitro root inoculation assay. Potato plantlets growing in squared petri dishes were inoculated by applying bacterial suspensions of $10^{7} \mathrm{CFU} / \mathrm{ml}$ along the roots. For each strain, three replicate petri dishes were sampled B, 1; C, 4; and D, 7 days after inoculation (DAI), and the plantlets were pooled and processed for internal bacterial density counts in root (R) and stem (S) sections. Bars represent standard error of the mean. Different letters on top of columns within each evaluation time and plant section indicate significant differences between strains (Tukey's multiple comparison test, $P=$ $0.05)$. 
showed an intermediate response but the differences were not statistically significant (Fig. 6D). Notably, the complemented mutant strain UY031 $\Delta$ Tfp-C achieved population levels comparable with those of strain UY031 during the whole timecourse colonization assay.

\section{DISCUSSION}

In this study, we used CGH on a spotted microarray reflecting the pan-genome of $R$. solanacearum to compare the gene content of strains exhibiting different virulence levels in order to identify candidate pathogenicity genes. Several previous studies revealed low genetic variation among IIB-1 $R$. solanacearum strains using fingerprinting genetic markers and sequence analysis of specific genes (Castillo and Greenberg 2007; Cellier and Prior 2010; Norman et al. 2009; Van der Wolf et al. 1998; Xue et al. 2011). The draft genomes of two strains from this group (UW551 and IPO1609) are now available, revealing almost an identical sequence and genome structure (Gabriel et al. 2006; Guidot et al. 2009b). In this study, we were able to detect variation among IIB-1 $R$. solanacearum strains, highlighting the CGH-microarray technology as a powerful way to perform whole genomic comparisons, even among closely related strains. Furthermore, with this approach, the low genetic variation among this group could be considered advantageous because it allowed us to identify a limited number of differential genes, therefore enhancing the probability of finding a correlation between genome composition and a particular phenotype.

In this work, a genomic comparison was performed in order to identify specific differences in gene content of $R$. solanacearum UY043. This strain was selected because it was isolated from soil, unlike the other strains that were isolated from potato tubers with typical bacterial wilt symptoms. In addition, this strain consistently displayed very low virulence on different hosts, including tomato, potato, and the wild species Solanum commersonii (Siri et al. 2011). Based on the particular traits of strain UY043, a comparative analysis was undertaken in order to allow insight into the putative genomic changes incurred in a strain from the environment, which may explain its low virulence. A major finding resulting from the analysis was the occurrence of a deletion in strain UY043 covering a 33.7$\mathrm{kb}$ region of the megaplasmid designated DR43. Validation by PCR amplification confirmed that all 25 genes contained in this region were absent in strain UY043 and present in 12 additional $R$. solanacearum strains from Uruguay, suggesting that this deletion event occurred exclusively in the environmental strain UY043.

Genomic rearrangements such as deletions, inversions, duplications, and transpositions have already been reported to occur naturally in $R$. solanacearum (González et al. 2011; Stevens and van Elsas 2010). These events are usually induced by the presence of insertion sequences and recombination hot-spot elements which are known to be scattered throughout the $R$. solanacearum genome (Salanoubat et al. 2002). Together with the ability to acquire new genetic information from other strains or species by horizontal gene transfer, these genomic rearrangements are responsible for the genome evolution and diversification of the $R$. solanacearum species complex.

Similar spontaneous deletions were reported by Guidot and associates (2009a), who applied the same CGH approach to investigate the extent of horizontal gene transfers and genomic rearrangements that occurred after natural transformation between different $R$. solanacearum strains. One of the genomic changes detected in this study was the loss of a cluster of 29.3 $\mathrm{kb}$ harboring 27 genes located within the megaplasmid (Guidot et al. 2009a). Remarkably, this DNA block is partially overlap- ping with the DR43 region which is deleted from strain UY043, suggesting that this region might be subjected to a high frequency of genomic rearrangements. A similar finding was reported by Stevens and van Elsas (2010), who used suppressive subtractive hybridization to compare a potato $R$. solanacearum IIB-1 strain with a related strain isolated from a water course. Following this approach, they identified a deletion of a putative genomic island of $17.6 \mathrm{~kb}$ in the environmental strain. This region, denoted PGI-1, is flanked by two insertion sequences elements, shows a low average $\mathrm{G}+\mathrm{C}$ content, and has several features that support the hypothesis that it constitutes a mobile genomic island. PGI-1 deletion does not affect pathogenicity on tomato but it was proposed to be involved in colonization fitness and adaptation to the plant local conditions (Stevens and van Elsas 2010; Stevens et al. 2011). Another deletion event in $R$. solanacearum was reported by González and associates (2011), who performed a comparative genomic analysis between two sequenced strains: IPO1609 and UW551. These closely related strains belong to the IIB-1 group but, in fact, appeared to differ significantly in their virulence toward host plants. In their work, the authors proved that IPO1609 indeed carries a 77-kb genomic deletion which is responsible for the almost complete loss of pathogenicity of the strain (González et al. 2011).

Analysis of the sequence of the DR43 homologous region in the draft sequence from strain IPO1609 revealed that this region is flanked by two highly homologous sequences corresponding to a partial sequence of a transposase gene. Therefore, it seems very likely that deletion of DR43 region resulted from a homologous recombination event between the two border sequences, leading to deletion of a DNA loop of $33.7 \mathrm{~kb}$ in strain UY043. It is interesting to note that comparison of the DR43 region from strain IPO1609 with the corresponding regions in $R$. solanacearum strains belonging to different phylotypes also revealed the occurrence of a genomic rearrangement within this region during evolution. On the other hand, high conservation regarding gene content and sequence homology within this region was found between phylotype II strains.

The annotation data of genes located within region DR43 strongly suggested that the loss of this region is associated with the low virulence found in strain UY043. In this study, we focused the analysis on a cluster of six genes involved in Tfp biogenesis. Tfp are widely distributed surface structures that mediate an extraordinary array of functions, including adhesion, biofilm formation, DNA uptake, and twitching motility (Pelicic 2008). It has been shown that these appendages also promote attachment to solid surfaces, including host tissues, and are considered to be important virulence factors in many pathogenic bacteria (Pizzarro-Cerdá and Cossart 2006). In contrast to the well-established role of Tfp in the pathogenicity of animal-pathogenic bacteria, their role in plant-pathogenic bacteria is poorly understood (Burdman et al. 2011). Previous studies reported that $\mathrm{Tfp}$ in $R$. solanacearum are involved in twitching motility, biofilm formation, and virulence (Kang et al. 2002; Liu et al. 2001; Wairuri et al. 2012).

Analysis of strain IPO1609 genome identified approximately 40 genes that encode putative proteins involved in the biogenesis and function of Tfp but, to date, little information exists regarding the function of most of these genes (Kang et al. 2002; Liu et al. 2001; Wairuri et al. 2012).

In this study, a cluster of six genes involved in Tfp biogenesis was identified within the DR43 region. This gene cluster showed identical distribution and high sequence conservation in all sequenced $R$. solanacearum strains. Furthermore, almost the same organization is found in other bacteria species, suggesting that the molecular mechanisms underlying biogenesis and functions of Tfp are conserved (Mattick 2002; Pelicic 
2008). Based on the nomenclature adopted for Pseudomonas aeruginosa, four of these genes were annotated in $R$. solanacearum as pilE1, pilX, pilW, and pilV. In addition, two Tfprelated genes are included in the cluster: RSIPO_04291, which encodes for a protein related to PilY1, and RSIPO_04295, encoding for a putative Tfp-related pilin. Interestingly, the PilY1 protein in $P$. aeruginosa shares sequence homology with the C-terminal regions of the PilC2 protein in Neisseria meningitidis. Indeed, for both species, these proteins are considered to be Tfp-associated adhesins required for twitching motility and adhesion to host cells (Kuchma et al. 2010; Rudel et al. 1995). The corresponding cluster in $P$. aeruginosa contained eight genes (pilE, pilY2, pilY1, pilV, pilW, pilX, fimT, and fimU). These proteins were designated as minor pilin-like proteins due to their limited abundance relative to the major pilin PilA (Koomey 1995). Many studies address the importance of minor pilins for biogenesis of functional pili; however, the role of these proteins may be variable among different model bacteria. In pathogenic Neisseria spp., these proteins modulate various Tfp-linked functions such as DNA uptake, bacterial aggregation, and adhesion but were found to be dispensable for Tfp biogenesis (Helaine et al. 2007). However, in P. aeruginosa, it was proposed that minor pilins are involved in the initiation of pilus assembly and are supposed to be incorporated into the growing fiber, playing an essential role in biogenesis of functional Tfp (Giltner et al. 2010). Recently, their importance in pilus assembly and virulence of $P$. syringae pv. tabaci was reported (Taguchi and Ichinose 2011). However, the importance of these proteins in other plant-pathogen interactions has not yet been addressed.

In this study, we showed that Tfp-related genes which are present in the DR43 region are involved in virulence of $R$. solanacearum. We previously found that strain UY043 displayed a reduced virulence assessed by soil inoculation on several hosts, including tomato, potato, and the wild potato relative S. commersonii (Siri et al. 2011). However, when plant inoculation was performed by placing the bacteria inside the stem, wilt symptoms were observed in a few days and no differences were detected from other $R$. solanacearum highly aggressive strains (Siri et al. 2011). It has been shown previously that blocking of Tfp pilin synthesis by inactivating pilA produced reduced virulence when both unwounded roots and wounded petioles of tomato plants were inoculated (Kang et al. 2002). Therefore, it was proposed that piliation could contribute to pathogenesis both during the invasion of roots and when the bacterium is inside plants (Kang et al. 2002). However, in this work, when strains were inoculated directly into the vascular system through a cut leaf petiole, all the tested strains caused the same level of disease on potato plants. This finding suggests that, once bacteria achieve the vascular system, the Tfp-related genes are no longer needed for disease development on potato. Interestingly, when soil inoculation was performed, a delayed appearance of symptoms was observed in plants inoculated with both UY031 $\Delta$ Tfp and UY043 strains compared with the highly aggressive strain UY031 and the complemented strain UY031 $\Delta$ Tfp-C. Together, these results suggest that minor pilins encoded by these particular Tfp-related genes mainly contribute to the early bacterial wilt pathogenesis, probably during the colonization of potato roots. Alternatively, these genes might control fitness of the bacteria during life in the soil.

To test this hypothesis, we applied an in vitro root inoculation assay to study colonization fitness on potato plants. Internal bacterial measurements in roots and stem tissues at 4 DAI revealed a similar reduction in the colonization ability for strains UY043 and UY031 1 Tfp in comparison with strain UY031 and the complemented strain UY031 $\mathrm{T}$ fp-C. This observation indicates that the reduced colonization fitness of strain UY043 could be attributed to the deletion of the cluster of Tfp-related genes located in the DR43 region. It seems likely that these genes contribute to Tfp biogenesis or function, thus reducing pathogen fitness during invasion of roots by affecting adherence to roots surfaces and migration to wound sites for colonization. On the other hand, at $7 \mathrm{DAI}$, mutant strain UY031 $\Delta$ Tfp exhibited an intermediate response between strain UY031 and UY043, in agreement with previous observations based on wilt symptoms development after soil inoculation. This finding suggests that additional pathogenicity determinants are involved in the low virulence observed for strain UY043.

Interestingly, there are two genes within the DR43 region which encoded for candidate effector proteins secreted through the T3SS. This secretion system plays a central role in the pathogenesis of $R$. solanacearum and many other plant and animal bacterial pathogens (Cornelis and Van Gijsegem 2000; Galán and Collmer 1999; He et al. 2004). Extensive studies were conducted to identify the repertoire of effector proteins (T3E) translocated into plant cells through the T3SS and, today, a refined list of $94 \mathrm{~T} 3 \mathrm{E}$ is recognized (Poueymiro and Genin 2009). Both candidate genes identified in this study (RSIPO_04287 and RSIPO_04310) are broadly conserved within the different strains of the species and have been demonstrated to be secreted in a T3SS-dependent manner in $R$. solanacearum (Mukaihara and Tamura 2009; Tamura et al. 2005). The gene RSIPO_04287 shares homology with the known T3E HopAA1-1 of $P$. syringae pv. tomato and was found to be directly regulated by $\mathrm{HrpB}$, an AraC-type transcriptional activator responsible for the expression of T3SS and T3E genes in R. solanacearum (Mukaihara et al. 2004; Occhialini et al. 2005). The gene RSIPO_04310 belongs to the SKWP effector family, which contain a novel amino acid repeat domain related to the heat/armadillo repeats from eukaryotes known to mediate protein-protein interactions. It was proposed that these proteins might interact with plant factors via the SKWP repeat domain to exert virulence functions (Mukaihara and Tamura 2009). Based on this information, it seems likely that both candidate genes could contribute to bacterial wilt development and their role in the pathogenesis of $R$. solanacearum will be the focus of future studies.

In summary, this study provides insights into the pathogenesis of $R$. solanacearum, in particular with regards to IIB-1 strains and the interaction with potato as its natural host. We identified a cluster of Tfp-related genes which contribute to the early bacterial wilt pathogenesis and colonization fitness of potato roots. Future studies are necessary to investigate the role of these genes in other Tfp-associated activities such as surface adherence and cell aggregation. Finally, this study highlights the occurrence of genomic rearrangements in $R$. solanacearum, which are known to play an important role in the evolution and diversification of the species. Examination of the genetic make-up of a larger collection of strains from different sources of isolation could contribute to understanding the importance of these phenomena in the potential adaptation of $R$. solanacearum strains to selective pressures from the environment.

\section{MATERIALS AND METHODS}

Bacterial strains, plasmids, and culture conditions.

Bacterial strains and plasmids used in this study are listed in Tables 1 and 2. $R$. solanacearum strains were routinely cultured at $28^{\circ} \mathrm{C}$ in either CPG (Hendrick and Sequiera 1984) or tetrazolium chloride (TZC) agar (Kelman 1954). Escherichia coli DH5 $\alpha$ used for genetic constructions was routinely cultured at $37^{\circ} \mathrm{C}$ in Luria-Bertani medium (Sambrook and Russell 2001). 
Antibiotics were added as required at the following final concentrations: ampicillin, $100 \mathrm{mg} / \mathrm{liter}$; spectinomycin, $40 \mathrm{mg} / \mathrm{liter}$; and tetracycline, $10 \mathrm{mg} /$ liter. The growth of $R$. solanacearum wild-type and mutant strains was compared in liquid MM (Bertolla et al. 1997) and in CPG medium. Triplicate cultures were inoculated with an initial optical density of 0.02 at 600 $\mathrm{nm}$ and bacterial growth was monitored by measuring changes in optical density over time (Tans-Kersten et al. 2001).

\section{CGH analysis.}

The repertoire of genes present in nine $R$. solanacearum strains isolated from potato fields in Uruguay in 2003 and 2004 was established from CGH experiments using a pangenomic microarray chip generated by $\mathrm{C}$. Boucher and collaborators (Guidot et al. 2009a). This spotted microarray consisted of 6,515 oligonucleotides containing genes identified from the genomes of three $R$. solanacearum strains belonging to different phylotypes or sequevars: GMI1000 (I-18), IPO1609 (IIB-1), and Molk2 (IIB-3). Genomic DNA was extracted from fresh bacterial cultures as described by Chen and Kuo (1993). Briefly, $1.5 \mathrm{ml}$ of an overnight culture was harvested with centrifugation for $3 \mathrm{~min}$ a $12,000 \mathrm{rpm}$. The pellet was resuspended in $200 \mu \mathrm{l}$ of lysis buffer (40 mM Tris-acetate [pH 7.8], $20 \mathrm{mM}$ sodium-acetate, $1 \mathrm{mM}$ EDTA, and $1 \%$ sodium dodecyl sulfate) by vigorous pipetting. To remove most proteins and cell debris, $66 \mu \mathrm{l}$ of $5 \mathrm{M} \mathrm{NaCl}$ solution was added and then the viscous mixture was centrifuged at $12,000 \mathrm{rpm}$ for $10 \mathrm{~min}$ at $4^{\circ} \mathrm{C}$. The clear supernatant was extracted with an equal volume of chloroform, transferred to another vial. Finally, DNA was precipitated with $100 \% \mathrm{EtOH}$, washed twice with $70 \% \mathrm{EtOH}$, air dried, and resuspended in $50 \mu \mathrm{l}$ of water.

Labeling of the genomic DNA from tested strains and microarray hybridization were performed as previously described (Guidot et al. 2009b). Hybridized microarrays were scanned using a GenePix 4000A dual-channel confocal laser scanner (Molecular Devices, Sunnyvale, CA, U.S.A.) at 532-nm (Cy3) and 645-nm (Cy5) excitation wavelengths, with a resolution of $10 \mathrm{~nm}$ per pixel. Quantification of the signals from individual arrays and data analysis were performed using ImaGene and Genesight software (BioDiscovery, Inc., Hawthorne, CA, U.S.A.). For each spot, the ratio of the hybridization signal of the tested strain to that of the reference control strains was calculated and $\log _{2}$ transformed and the values were normalized (Guidot et al. 2009b). The presence or absence of a gene in each tested strain was determined by comparing the average $\log _{2}$ ratio value thus calculated with the cut-off value of -1 .

Table 1. Ralstonia solanacearum strains, plasmids, and primers used in this study

\begin{tabular}{|c|c|c|c|c|c|c|}
\hline \multirow[b]{2}{*}{ Strain $^{\text {a }}$} & \multicolumn{3}{|c|}{ Origin } & \multirow[b]{2}{*}{ Phylotype-sequevar } & \multirow[b]{2}{*}{ Aggressiveness $^{\text {b }}$} & \multirow[b]{2}{*}{ Analysis $^{c}$} \\
\hline & Year & Origin & Sample & & & \\
\hline UY031 & 2003 & Uruguay & Potato & IIB-1 & High & CGH, PCR \\
\hline UY032 & 2003 & Uruguay & Potato & IIB-1 & High & CGH, PCR \\
\hline UY033 & 2003 & Uruguay & Potato & IIB-1 & Low & CGH, PCR \\
\hline UY034 & 2003 & Uruguay & Potato & IIB-1 & High & CGH, PCR \\
\hline UY035 & 2003 & Uruguay & Potato & IIB-1 & Low & CGH, PCR \\
\hline UY036 & 2003 & Uruguay & Potato & IIB-1 & High & CGH, PCR \\
\hline UY041 & 2004 & Uruguay & Potato & IIB-1 & High & CGH, PCR \\
\hline UY042 & 2004 & Uruguay & Potato & IIB-1 & High & CGH, PCR \\
\hline UY043 & 2004 & Uruguay & Soil & IIB-1 & Low & CGH, PCR \\
\hline UY082 & 2008 & Uruguay & Potato & IIB-1 & High & PCR \\
\hline UY084 & 2008 & Uruguay & Potato & IIB-1 & High & PCR \\
\hline UY087 & 2008 & Uruguay & Potato & IIB-1 & High & PCR \\
\hline UY091 & 2009 & Uruguay & Potato & IIB-1 & High & PCR \\
\hline IPO1609 & 1995 & Netherlands & Potato & IIB-1 & Medium & CGH, PCR \\
\hline GMI1000 & 1978 & French Guyana & Tomato & $\mathrm{I}-18$ & ND & CGH, PCR \\
\hline
\end{tabular}

${ }^{a} R$. solanacearum wild-type strains.

b Virulence on tomato ('Loica'), potato ('Chieftain'), and the wild potato relative Solanum commersonii (Siri et al. 2011).

${ }^{\mathrm{c}} \mathrm{CGH}=$ comparative genomic hybridization, $\mathrm{PCR}=$ polymerase chain reaction, $\mathrm{ND}=$ not determined.

Table 2. Ralstonia solanacearum mutant strains, plasmids and primers used for genetic constructions

\begin{tabular}{|c|c|c|}
\hline Strain, plasmid, or primer & Relevant characteristics $^{\text {a }}$ & Reference or source \\
\hline \multicolumn{3}{|l|}{ Strains } \\
\hline UY031 0 Tfp & Recombinant of strain UY031 by pGRU $\Omega D, \mathrm{Sp}^{\mathrm{r}}$ & This study \\
\hline UY031 $\Delta$ Tfp-C & UY031 0 Tfp complemented with pLAFR6-Tfp43, $\mathrm{Sp}^{\mathrm{r}}, \mathrm{Tc}^{\mathrm{r}}$ & This study \\
\hline \multicolumn{3}{|c|}{ 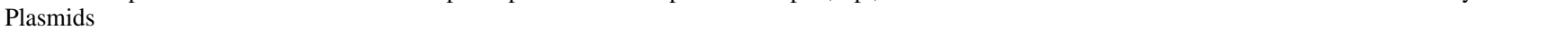 } \\
\hline pGEM-T easy & Cloning vector, $\mathrm{Ap}^{\mathrm{r}}$ & Promega Corp. \\
\hline pGRU & PCR-amplified (1,300-bp) RSIPO_04290 upstream fragment, cloned in pGEM-T easy, Ap ${ }^{\mathrm{r}}$ & This study \\
\hline pGRD & PCR-amplified (1,450-bp) RSIPO_04295 downstream fragment, cloned in pGEM-T easy, Ap ${ }^{\mathrm{r}}$ & This study \\
\hline pGRUD & 1,450-bp insert from pGRD cloned into XbaI-SacI sites of pGRU, Ap ${ }^{r}$ & This study \\
\hline pGRU $\Omega D$ & 2,000-bp $\Omega$ cassette inserted into BamHI sites of pGRUD, $\mathrm{Sp}^{\mathrm{r}}, \mathrm{Ap}^{\mathrm{r}}$ & This study \\
\hline pLAFR6 & pLAFR1 with trp terminator, $\mathrm{Tc}^{\mathrm{r}}$ & Huynh et al. 1989 \\
\hline pLAFR6-Tfp43 & $\begin{array}{l}\text { 6,800-bp fragment containing the cluster of Tfp related genes (RSIPO_04290-RSIPO_04295) } \\
\text { cloned into the HindIII site of pLAFR6, Tc }{ }^{r}\end{array}$ & This study \\
\hline \multicolumn{3}{|c|}{ (1) } \\
\hline U4290-F & 5'-TCTAGATGAACATGAACGAGGTGCTC-3' (XbaI) & This study \\
\hline U4290-R & $5^{\prime}$-GGATCCTCAATCAGTTGGGTGTGC-3' (BamHI) & This study \\
\hline D4295-F & 5'-GGATCCAGCGAACGGTATACGGAATG-3' (BamHI) & This study \\
\hline D4295-R & 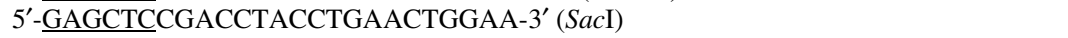 & This study \\
\hline Tfp43-F & 5'- & This study \\
\hline Tfp43-R & 5'-AAGCTTGTGTTCTGTGGCAAGCAAGC-3' (HindIII) & This study \\
\hline
\end{tabular}

${ }^{a} \mathrm{Ap}^{\mathrm{r}}, \mathrm{Sp}^{\mathrm{r}}$, and $\mathrm{Tc}^{\mathrm{r}}=$ resistant to ampicillin $(\mathrm{Ap})$, spectinomycin $(\mathrm{Sp})$, and tetracycline $(\mathrm{Tc})$, respectively; PCR $=$ polymerase chain reaction. Underlined sequences correspond to restriction sites incorporated in primers corresponding to the enzymes specified in parenthesis. 
Lists of candidate pathogenicity genes were generated by comparing the gene repertoire of each strain and selecting specific genes for strains with differences in virulence or source of isolation. For candidate genes referred to in the microarray with the designation of strain GMI1000, the corresponding homo$\log$ in strain IPO1609 was searched using Basic Local Alignment Search Tool (BLAST).

\section{PCR amplification of candidate pathogenicity genes.}

PCR amplification was performed using specific primers designed for each candidate gene based on the genome sequence of strain IPO1609 because it belongs to the same group (IIB-1) as strains isolated in Uruguay. For candidate genes with no homolog in IPO1609 (BLAST $P$ identity $<80 \%$ ), primers were designed based on the sequence of strain GMI1000. Amplification was performed over 11 virulent $R$. solanacearum strains (6 of which were also used for CGH experiments) and 3 weakly virulent strains (all used for CGH experiments) (Table 1). PCR reactions were conducted in a total volume of $25 \mu \mathrm{l}$ containing $1 \times$ DNA polymerase buffer, $1.5 \mathrm{mM} \mathrm{MgCl}_{2}, 10 \mathrm{pmol}$ of each forward and reverse primers, $0.2 \mathrm{mM}$ each of four dNTPs, 1 U of Taq DNA polymerase (Invitrogen, Life Technologies Corporation, Carlsbad, CA, U.S.A.), and $100 \mathrm{ng}$ of genomic DNA. Amplification conditions included an initial denaturation step at $96^{\circ} \mathrm{C}$ for $5 \mathrm{~min}$; followed by 35 cycles of $94^{\circ} \mathrm{C}$ for $20 \mathrm{~s}, 59^{\circ} \mathrm{C}$ for $30 \mathrm{~s}$, and $72^{\circ} \mathrm{C}$ for $30 \mathrm{~s}$; with a final extension step of $72^{\circ} \mathrm{C}$ for $10 \mathrm{~min}$. Non-template control and positive controls (IPO1609 or GMI1000 DNA) were included in each experiment. PCR products $(8 \mu \mathrm{l})$ were analyzed by electrophoresis through $1.2 \%$ (wt/vol) agarose gels with ethidium bromide at $0.5 \mu \mathrm{g} / \mathrm{ml}$ and photographed under UV light.

\section{General DNA manipulation and sequence analysis.}

Molecular cloning procedures, including preparation of competent cells, ligation, transformation of E. coli by electroporation, genomic DNA extraction, and DNA restriction and analysis, were performed according to standard protocols (Ausubel et al. 1994; Sambrook and Russell 2001). Restriction enzymes, DNA ligase, and other DNA enzymes were used according to the manufacturers' recommendations. Plasmid DNA was isolated using Wizard Plus SV Minipreps DNA Purification System (Promega Corp., Madison, WI). DNA sequencing and oligonucleotide synthesis were performed by Macrogen services (Kumchun-ku, Seoul, Korea).

\section{Construction of $R$. solanacearum mutant strain UY031 $\Delta$ Tfp.}

An $R$. solanacearum mutant strain was generated by inserting the $\Omega$ interposon carrying a spectinomycin resistance gene (Prentki and Krisch 1984) in substitution of the gene cluster comprised between genes RSIPO_04290 and RSIPO_04295 in the highly aggressive strain UY031. Primers were designed based on strain IPO1609 genome draft in order to amplify a 1,300-bp fragment located upstream of the gene RSIPO_04290 (primer pair U4290-F/U4290-R) and a 1,450bp fragment downstream of the gene RSIPO_04295 (primer pair D4295-F/D4295-R) (Table 2). Specific restriction sites were incorporated to each primer to be used in subsequent cloning steps. The PCRs were performed in $25-\mu 1$ reaction mixtures containing $1 \times$ Phusion GC buffer (with $\mathrm{MgCl}_{2}$ ), $1.25 \mathrm{U}$ of Phusion DNA polymerase (New England Biolabs, Inc., Ipswich, MA, U.S.A.), dNTPs (0.2 mM each), forward and reverse primers $(0.4 \mu \mathrm{M}$ each), and $50 \mathrm{ng}$ of genomic DNA from strain UY031 as template. The thermocycling conditions were $98^{\circ} \mathrm{C}$ for $30 \mathrm{~s} ; 35$ cycles of $98^{\circ} \mathrm{C}$ for $10 \mathrm{~s}, 60^{\circ} \mathrm{C}$ for $30 \mathrm{~s}$, and $72^{\circ} \mathrm{C}$ for $45 \mathrm{~s}$; and a final extension step at $72^{\circ} \mathrm{C}$ for $5 \mathrm{~min}$. The resulting fragments were cloned into pGEM-T easy (Promega
Corp.), creating pGRU for the upstream border of gene RSIPO_ 04290 and pGRD for the downstream border of gene RSIPO_ 04295. Inserts were confirmed by sequencing with vector primers SP6 and T7. The insert from pGRD was excised by double digestion with BamHI and SacI, and inserted into pGRU to produce pGRUD. The $\Omega$-spectinomycin resistance cassette was introduced into pGRUD at the unique BamHI site located between upstream and downstream fragments, generating pGRU $\Omega D$. This construction was verified by multiple digestions (BamHI, BamHI/SacI, and BamHI/ScaI) and sequencing. Finally, pGRU $\Omega D$ was introduced into the genome of wildtype $R$. solanacearum UY031 by natural transformation and homologous double recombination following the protocol described by Boucher and associates (1985). A spectinomycinresistant recombinant with typical colony morphology in TZC medium was selected and was PCR verified that the region extending from RSIPO_04290 to RSIPO_04295 has been deleted and replaced by the $\bar{\Omega}$ interposon. This mutant strain, denoted as UY031 $\Delta$ Tfp, was used for phenotypic characterization.

\section{Complementation of UY031 $\Delta \mathrm{Tfp}$.}

A 6,800-bp fragment covering the full length of the Tfprelated gene cluster (RSIPO_04290 and RSIPO_04295) was PCR amplified with primers Tfp43-F and Tfp43-R (Table 2). This amplicon was cloned into the HindIII site of the broadrange plasmid pLAFR6 (Huynh et al. 1989) to generate pLAFR-Tfp43. This plasmid was introduced into the mutant strain UY031 $\Delta$ Tfp by natural transformation as described above and trans-complemented strains were selected by spectinomycin and tetracycline resistance on TZC agar. The complemented mutant strain selected for further studies was designated UY031 $\Delta$ Tfp-C.

\section{TEM.}

Cultures of the $R$. solanacearum strains were prepared for TEM following the procedure described by Kang and associates (2002), with minor modifications. Briefly, drops of phosphate buffer were deposited on 48-h-old $R$. solanacearum colonies on the surface of CPG plates and, within 30 s, a 200mesh Formvar-coated copper grid was floated on the surface of each drop. The grids were removed and floated on a drop of $2 \%$ uranyle acetate for $1 \mathrm{~min}$, and then excess dye was removed. Grids were dried and examined in a JEOL JEM 1010 operated at $100 \mathrm{kV}$ and the images were taken with a digital camera (Hamamatsu C4742-95) at magnification $\times 25,000, \times 30,000$, or $\times 50,000$.

\section{Twitching motility assay.}

To observe twitching motility, plates were prepared and incubated as described by Liu and associates (2001), with minor modifications. Briefly, freshly poured CPG plates were dried by removing their lids and placing them inverted in a $37^{\circ} \mathrm{C}$ incubator for 10 to $30 \mathrm{~min}$. Inoculation was performed by spotting microdroplets $(10 \mu \mathrm{l})$ of cell suspensions adjusted to $10^{5} \mathrm{CFU} / \mathrm{ml}$ on the surface of the plate. Plates were incubated at $28^{\circ} \mathrm{C}$ in a loosely closed plastic bag along with several moist paper towels to ensure high humidity. After 24 to $48 \mathrm{~h}$, colonies were examined for twitching motility by placing a petri dish without its lid on the stage of an upright light microscope (Nikon Eclipse $80 i$ ) using the $\times 20$ objective.

\section{Biofilm assay.}

Biofilm formation was determined using a quantitative plate assay (O'Toole and Kolter 1998), with minor modifications. Briefly, 96-well PVC microtiter plates containing $90 \mu \mathrm{l}$ of CPG broth per well were inoculated with $10 \mu \mathrm{l}$ of bacterial suspensions adjusted to $10^{8} \mathrm{CFU} / \mathrm{ml}$ (optical density at $600 \mathrm{~nm}$ 
of 0.1 ). The plates were sealed with plastic wrap and incubated without shaking for $48 \mathrm{~h}$ at $28^{\circ} \mathrm{C}$. Then, cultures were poured out and wells rinsed with distilled water. Biofilms were stained by adding $100 \mu \mathrm{l}$ of a $0.1 \%$ crystal violet solution to each well. After $30 \mathrm{~min}$, plates were rinsed with distilled water and analyzed quantitatively by solubilizing the stained biofilms with 95\% ethanol for $30 \mathrm{~min}$ and measuring the optical density at $590 \mathrm{~nm}$ of the stained suspension in a spectrophotometer.

\section{Plant assays.}

The virulence of wild-type strains (UY031 and UY043) and mutant strain UY031 $\Delta$ Tfp was measured on susceptible $S$. tuberosum 'Chieftain', using both a direct petiole inoculation and a soil inoculation procedure, as previously described (Siri et al. 2011). Plantlets were micropropagated from single-node pieces growing in vitro on Murashige and Skoog (MS) medium supplemented with sucrose at $30 \mathrm{~g} /$ liter and maintained at $22^{\circ} \mathrm{C}$ with a 16-h photoperiod. After 3 weeks, plantlets were transferred into plastic flats with $17-\mathrm{cm}^{3}$ cells containing commercial soil mix (TREF, Moerdijk, The Netherlands) and placed for acclimatization in a greenhouse at 22 to $25^{\circ} \mathrm{C}$ under natural light for 2 weeks prior to inoculation. To prepare the inocula, strains were grown overnight at $28^{\circ} \mathrm{C}$ and agitation at $200 \mathrm{rpm}$ in liquid CPG or CPG-spectinomycin for wild-type and mutant strains, respectively. Cells were pelleted by centrifugation, suspended in $0.9 \%$ saline solution, and spectrophotometrically adjusted to $10^{8} \mathrm{CFU} / \mathrm{ml}$ (optical density at $600 \mathrm{~nm}$ of 0.1 ). Inocula concentrations were checked by dilution plating on TZC or TZC-spectinomycin agar to observe typical smooth colonies after 2 days of incubation at $28^{\circ} \mathrm{C}$. These suspensions were used directly or diluted in sterile saline solution for plant inoculations.

For direct petiole inoculation, the third true leaf from the top of the plant was excised $5 \mathrm{~mm}$ from its base, and a $10-\mu 1$ droplet of a bacterial suspension diluted to $10^{5} \mathrm{CFU} / \mathrm{ml}$ was placed onto the cut surface (equivalent to 1,000 cells). Then, 5 replicate plants were inoculated with each strain in a completely randomized design and the experiment was repeated twice, giving a total of 10 tested plants for each strain.

For soil inoculation, roots were slightly damaged by making a hole with a $1,000-\mu 1$ disposable pipette tip next to each plant; then, $1 \mathrm{ml}$ of the bacterial suspension adjusted to $10^{8} \mathrm{CFU} / \mathrm{ml}$ was poured inside the hole $\left(5 \times 10^{8} \mathrm{CFU} / \mathrm{g}\right.$ of soil). In total, 10 potato plants were inoculated with each strain and placed in separated trays in order to prevent cross contamination. Three replicate trays were assayed for each strain in a completely randomized design and the experiment was repeated twice under the same conditions.

Plants inoculated with saline solution were used as negative controls in all experiments. After inoculation, plants were incubated in a growth chamber at $28^{\circ} \mathrm{C}$ with a 16 -h photoperiod. Disease development was recorded at regular time intervals using an ordinal scale ranging from 0 (no wilting symptoms) to 4 (all leaves wilted) up to 21 DAI (Winstead and Kelman 1952). Strain virulence was estimated by the area under disease progression curve based on average wilt scoring for each strain and inoculation method.

\section{Colonization assays.}

To study colonization fitness of wild-type and mutant $R$. solanacearum strains, bacterial populations in $S$. tuberosum Chieftain plants were measured after an in vitro root inoculation assay adapted from Vailleau and associates (2007). Experiments were performed with plantlets growing in axenic conditions in nutrient MS medium supplemented with $30 \mathrm{~g}$ of sucrose and $0.1 \mathrm{mg}$ of indole-3-butyric acid per liter. Potato plantlets were grown from single-node pieces in square petri dishes (12 by $12 \mathrm{~cm}$ ), with solid nutrient medium covered with filter paper in order to force the roots to grow on the surface. petri dishes were sealed with Parafilm, with several incisions to allow gas exchange, and maintained inclined with an angle of 45 degrees at $22^{\circ} \mathrm{C}$ with a 16 -h photoperiod. After 2 weeks, plantlets were inoculated on intact root tips by applying $0.3 \mathrm{ml}$ of a bacterial suspension adjusted to $10^{7} \mathrm{CFU} / \mathrm{ml}$ along the entire length of roots. Petri dishes containing six plantlets were inoculated with each tested strain in a completely randomized design and held inclined in a growth chamber at $28^{\circ} \mathrm{C}$ with a $16-h$ photoperiod. Negative controls were carried out using the same procedure with saline solution. After 1, 4, and 7 days, three replicate petri dishes inoculated with each strain were harvested, and the plantlets were pooled and processed for internal bacterial density counts. Root systems and stem segments (approximately $3 \mathrm{~cm}$ in length) were removed from each plant and assayed separately. Plant tissues were surface sterilized by immersion in $1.0 \%$ sodium hypochlorite solution for $1 \mathrm{~min}$, washed three times with sterile water, and dried with absorbent paper. Each sample was weighted and ground in $5 \mathrm{ml}$ of distilled water by use of sand with a mortar and pestle. The resulting root and stem homogenates were subjected to 10 -fold serial dilutions and plated onto TZC or TZC-spectinomycin agar medium, and colonies were counted after 2 days of incubation at $28^{\circ} \mathrm{C}$. $R$. solanacearum population densities were normalized to $\log (\mathrm{CFU} / \mathrm{g})$ of plant tissue.

\section{Data analysis.}

All quantitative assays were analyzed by using analysis of variance and the Tukey's test was applied for mean comparison among treatments at the $95 \%$ confidence level. All statistical analysis was performed by using Infostat software (Di Rienzo et al. 2009).

\section{ACKNOWLEDGMENTS}

We thank M. Valls and S. Genin for helpful discussions, A. Castillo for technical advice and logistical support with in vitro plant propagation, and G. Casanova for assistance with TEM observations. This work was supported by grants PDT 54/190 and CSIC I+D-Grupos number 652 and Ph.D. scholarships provided to M. I. Siri by the Basics Sciences Development Program from Uruguay (PEDECIBA) and the National Research Council in Uruguay (ANII). M. I. Siri was allowed travel fellowships from the French Embassy in Uruguay, ANII, and PEDECIBA for stays in C. Boucher's lab in Toulouse to perform CGH experiments and genetic constructions.

\section{LITERATURE CITED}

Ausubel, F. H., Brent, R., Kingston, R. E., Moore, D. D., Seidman, J. G. Smith, J. A., and Struth, K. 1994. Current Protocols in Molecular Biology. John Wiley and Sons, Mississauga, Canada.

Bertolla, F., Van Gijsegem, F., Nesme, X., and Simonet, P. 1997. Conditions for natural transformation of Ralstonia solanacearum. Appl. Environ. Microbiol. 63:4965-4968.

Boucher, C., Martinel, A., Barberis, P., Alloing, G., and Zischek, C. 1985. Virulence genes are carried by a megaplasmid of the plant pathogen Pseudomonas solanacearum. Mol. Gen. Genet. 205:270-275.

Brown, D., and Allen, C. 2004. Ralstonia solanacearum genes induced during growth in tomato: An inside view of bacterial wilt. Mol. Microbiol. 53:1641-1660.

Buddenhagen, I., and Kelman, A. 1964. Biological and physiological aspects of bacterial wilt caused by Pseudomonas solanacearum. Annu. Rev. Phytopathol. 2:203-230.

Buddenhagen, I., Sequeira, L., and Kelman, A. 1962. Designation of races in Pseudomonas solanacearum. (Abstr.) Phytopathology 52:726.

Burdman, S., Bahar, O., Parker J. K., and De La Fuente, L. 2011. Involvement of type IV pili in the pathogenicity of plant pathogenic bacteria. Genes 2:706-735.

Castillo, J. A., and Greenberg, J. T. 2007. Evolutionary dynamics of Ralstonia solanacearum. Appl. Environ. Microbiol. 73:1225-1238.

Cellier, G., and Prior, P. 2010. Deciphering phenotypic diversity of Ral- 
stonia solanacearum strains pathogenic to potato. Phytopathology 100:1250-1261.

Chen, W. P., and Kuo, T. T. 1993. A simple and rapid method for the preparation of gram-negative genomic DNA. Nucleic Acids Res. 21:2260.

Cornelis, G. R., and Van Gijsegem, F. 2000. Assembly and function of type III secretory systems. Annu. Rev. Microbiol. 54:735-774.

Coutinho, T. A. 2005. Introduction and prospectus of the survival of $R$. solanacearum. Pages 29-38 in: Bacterial Wilt: The Disease and the Ralstonia solanacearum Species Complex. C. Allen, P. Prior, and A. C. Hayward, eds. American Phytopathological Society, St. Paul, MN, U.S.A.

Di Rienzo, J. A., Casanoves, F., Balzarini, M. G., Gonzalez, L., Tablada, M., and Robledo C. W. InfoStat versión 2009. Grupo InfoStat, FCA, Universidad Nacional de Córdoba, Argentina.

Elphinstone, J. G. 2005. The current bacterial wilt situation: A global overview. Pages 9-28 in: Bacterial Wilt: The Disease and the Ralstonia solanacearum Species Complex. C. Allen, P. Prior, and A. C. Hayward, eds. American Phytopathological Society, St. Paul, MN, U.S.A.

Fegan, M., and Prior, P. 2005. How complex is the 'Ralstonia solanacearum' species complex? Pages 449-461 in: Bacterial Wilt: The Disease and the Ralstonia solanacearum Species Complex. C. Allen, P. Prior, and A. C. Hayward, eds. American Phytopathological Society, St. Paul, MN, U.S.A.

Gabriel, D. W., Allen, C., Schell, M., Denny, T. P., Greenberg, J. T., Duan, Y. P., Flores-Cruz, Z., Huang, Q., Clifford, J. M., Presting, G., González, E. T., Reddy J., Elphinstone, J., Swanson, J., Yao, J., Mulholland, V., Liu, L., Farmerie, W., Patnaikuni, M., Balogh, B., Norman, D., Alvarez, A., Castillo, J. A., Jones, J., Saddler, G., Walunas, T., Zhukov, A., and Mikhailova, N. 2006. Identification of open reading frames unique to a select agent: Ralstonia solanacearum race 3 biovar 2. Mol. PlantMicrobe Interact. 19:69-79.

Galán, J. E., and Collmer, A. 1999. Type III secretion machines: Bacterial devices for protein delivery into host cells. Science 284:1322-1328.

Genin, S., and Boucher, C. 2004. Lessons learned from the genome analysis of Ralstonia solanacearum. Annu. Rev. Phytopathol.42:107-134.

Genin, S., and Denny, T. P. 2012. Pathogenomics of the Ralstonia solanacearum species complex. Annu. Rev. Phytopathol. 50:4.1-4.23

Giltner, C. L., Habash, M., and Burrows, L. L. 2010. Pseudomonas aeruginosa minor pilins are incorporated into type IV pili. J. Mol. Biol. 398:444-461.

González, A., Plener, L., Restrepo, S., Boucher, C., and Genin, S. 2011. Detection and functional characterization of a large genomic deletion resulting in decreased pathogenicity in Ralstonia solanacearum race 3 biovar 2 strains. Environ. Microbiol. 12:3172-3185.

Guidot, A., Prior, P., Schoenfeld, J., Carrere, S., Genin, S., and Boucher, C. 2007. Genomic structure and phylogeny of the plant pathogen Ralstonia solanacearum inferred from gene distribution analysis. J. Bacteriol. 189:377-387

Guidot, A., Coupat, B., Fall, S., Prior, P., and Bertolla, F. 2009a. Horizontal gene transfer between Ralstonia solanacearum strains detected by comparative genomic hybridization on microarrays. ISME J. 3:549-562.

Guidot, A., Elbaz, M., Carrere, S., Siri, M. I., Pianzzola, M. J., Prior, P., and Boucher, C. 2009b. Specific genes from the potato brown rot strains of Ralstonia solanacearum and their potential use for strain detection. Phytopathology 99:1105-1112.

Hayward, A. C. 1991. Biology and epidemiology of bacterial wilt caused by Pseudomonas solanacearum. Annu. Rev. Phytopathol. 29:65-87.

Hayward, A. C. 1994a. Systematics and phylogeny of Pseudomonas solanacearum and related bacteria. Pages 123-135 in: Bacterial Wilt: The Disease and Its Causative Agent, Pseudomonas solanacearum. A. C. Hayward and G. L. Hartman, eds. CAB International, Wallingford, U.K.

Hayward, A. C. 1994b. The hosts of Pseudomonas solanacearum. Pages 9 24 in: Bacterial Wilt: The Disease and Its Causative Agent, Pseudomonas solanacearum. A. C. Hayward and G. L. Hartman, eds. CAB International, Wallingford, U.K.

He, S. Y., Nomura, K., and Whittam, T. S. 2004. Type III protein secretion mechanism in mammalian and plant pathogens. Biochim. Biophys. Acta 1694:181-206.

Helaine, S., Dyer, D. H., Nassif, X., Pelicic, V., and Forest, K. T. 2007. 3D structure/function analysis of PilX reveals how minor pilins can modulate the virulence properties of type IV pili. Proc. Natl. Acad. Sci. U.S.A. 104:15888-15893.

Hendrick, C., and Sequeira, L. 1984. Lipopolysaccharide-defective mutants of the wilt pathogen Pseudomonas solanacearum. Appl. Environ. Microbiol. 48:94-101

Huynh, T. V., Dahlbeck, D., and Staskawicz, B.J. 1989. Bacterial blight of soybean: Regulation of a pathogen gene determining host cultivar specificity. Science 245:1374-1377.

Janse, J. D. 1996. Potato brown rot in western Europe-history, present occurrence and some remarks on possible origin, epidemiology and control strategies. Bull. EPPO/OEPP Bull. 26:679-695.

Kang, Y., Liu, H., Genin, S., Schell, M. A., and Denny, T. P. 2002. Ralstonia solanacearum requires type 4 pili to adhere to multiple surfaces and for natural transformation and virulence. Mol. Microbiol. 46:427437.

Kelman, A. 1954. The relationship of pathogenicity of Pseudomonas solanacearum to colony appearance in tetrazolium medium. Phytopathology 44:693-695.

Koomey, M. 1995. Prepilin-like molecules in type 4 pilus biogenesis: Minor subunits, chaperones or mediators of organelle translocation? Trends Microbiol. 3:409-410.

Kuchma, S. L., Ballok, A. E., Merritt, J. H., Hammond, J. H., Lu, W. Rabinowitz, J. D., and O'Toole, G. A. 2010. Cyclic-di-GMP-mediated repression of swarming motility by Pseudomonas aeruginosa: The pilY1 gene and its impact on surface-associated behaviors. J. Bacteriol. 192:2950-2964.

Lin, Y.-M., Chou, I.-C., Wang, J.-F., Ho, F.-I., Chu, Y.-J., Huang, P.-C-, Lu, D.-K., Shen, H.-L-, Elbaz, M., Huang, S.-M., and Cheng, C.-P. 2008. Transposon mutagenesis reveals differential pathogenesis of Ralstonia solanacearum on tomato and Arabidopsis. Mol. Plant-Microbe Interact. 21:1261-1270.

Liu, H., Kang, Y., Genin, S., Schell, M. A., and Denny, T. P. 2001. Twitching motility of Ralstonia solanacearum requires a type IV pilus system. Microbiology 147:3215-3229.

Mattick, J. S. 2002. Type IV pili and twitching motility. Annu. Rev. Microbiol. 56:289-314.

Mukaihara, T., and Tamura, N. 2009. Identification of novel Ralstonia solanacearum type III effectors proteins through translocation analysis of hrpB-regulated gene products. Microbiology 155:2235-2244.

Mukaihara, T., Tamura, N., Murata, Y., and Iwabuchi, M. 2004. Genetic screening of Hrp type III-related pathogenicity genes controlled by the HrpB transcriptional activator in Ralstonia solanacearum. Mol. Microbiol. 54:863-875

Norman, D., Zapata, M., Gabriel, D., Duan, Y. P., Yuen, J. M. F., Mangravita-Novo, A., and Donahoo, R. S. 2009. Genetic diversity and host range variation of Ralstonia solanacearum strains entering North America. Phytopathology 99:1070-1077.

Occhialini, A., Cunnac, S., Reymond, N., Genin, S., and Boucher, C. 2005. Genomewide analysis of gene expression in Ralstonia solanacearum reveals that the $h r p B$ gene acts as a regulatory switch controlling multiple virulence pathways. Mol. Plant-Microbe Interact. 18:938-949.

O'Toole, G. A., and Kolter, R. 1998. Flagellar and twitching motility are necessary for Pseudomonas aeruginosa biofilm development. Mol. Microbiol. 30:295-304.

Pelicic, V. 2008. Type IV pili: E pluribus unum? Mol. Microbiol. 68:827837.

Pizarro-Cerdá, J., and Cossart, P. 2006. Bacterial adhesion and entry into host cells. Cell 124:715-727.

Prentki, P., and Kirsch, H. M. 1984. In vitro insertional mutagenesis with a selectable DNA fragment. Gene 29:303-313.

Poueymiro, M., and Genin, S. 2009. Secreted proteins from Ralstonia solanacearum: A hundred tricks to kill a plant. Curr. Opin. Microbiol. 12:44-52.

Remenant, B., Coupat-Goutaland, B., Guidot, A., Cellier, G., Wicker, E., Allen, C., Fegan, M., Pruvost, O., Elbaz, M., Calteau, A., Salvignol, G., Mornico, D., Mangenot, S., Barbe, V., Médigue, C., and Prior, P. 2010. Genomes of three tomato pathogens within the Ralstonia solanacearum species complex reveal significant evolutionary divergence. BMC Genomics 11:379.

Rudel, T., Scheurerpflug, I., and Meyer, T. F. 1995. Neisseria PilC protein identified as type 4 pilus tip-located adhesin. Nature 373:357-359.

Salanoubat, M., Genin, S., Artiguenave, F., Gouzy, J., Mangenot, S., Arlat, M., Billault, A., Brottier, P., Camus, J. C., Cattolico, L., Chandler, M. Choisne, N., Claudel-Renard, C., Cunnac, S., Demange, N., Gaspin, C., Lavie, M., Moisan, A., Robert, C., Saurin, W., Schiex, T., Siguier, P., Thebault, P., Whalen, M., Wincker, P., Levy, M., Weissenbach, J., and Boucher, C. 2002. Genome sequence of the plant pathogen Ralstonia solanacearum. Nature 415:497-502.

Sambrook, J., and Russell, D. W. 2001. Molecular Cloning: A Laboratory Manual, 3rd ed. Cold Spring Harbor Laboratory Press, Cold Spring Harbor, NY, U.S.A

Schell, M. A. 2000. Control of virulence and pathogenicity genes of Ralstonia solanacearum by an elaborate sensory array. Annu. Rev. Phytopathol. 38:263-292

Siri, M. I., Sanabria, A., and Pianzzola, M. J. 2011. Genetic diversity and aggressiveness of Ralstonia solanacearum strains causing bacterial wilt of potato in Uruguay. Plant Dis. 95:1292-1301.

Stevens, P., and van Elsas, J. D. 2010. A putative genomic island, PGI-1, 
in Ralstonia solanacearum biovar 2 revealed by subtractive hybridization. Antonie Leeuwenhoek 98:359-377.

Stevens, P., van Overbeek, L. S., and van Elsas, J. D. 2011. Ralstonia solanacearum $\triangle \mathrm{PGI}-1$ strain KZR-5 is affected in growth, response to cold stress and invasion of tomato. Microb. Ecol. 61:101-112.

Swanson, J. K., Yao, J., Tans-Kersten, J. K., and Allen, C. 2005. Behavior of Ralstonia solanacearum race 3 biovar 2 during latent active infection of geranium. Phytopathology 95:136-143.

Taguchi, F., and Ichinose, Y. 2011. Role of type IV pili in virulence of Pseudomonas syringae pv. tabaci 6605: Correlation of motility, multidrug resistance, and HR-inducing activity on a non host plant. Mol. Plant Microbe Interact. 24:1001-1011.

Tamura, N., Murata, Y., and Mukaihara, T. 2005. Isolation of Ralstonia solanacearum $\operatorname{hrpB}$ constitutive mutants and secretion analysis of $h r p B$-regulated gene products that share homology with known type III effectors and enzymes. Microbiology 151:2873-2884.

Tans-Kersten, J. K., Huang, H., and Allen, C. 2001. Ralstonia solanacearum needs motility for invasive virulence on tomato. J. Bacteriol. 183:3597-3605

Vailleau, F., Sartorel, E., Jardinaud, M. F., Chardon, F., Genin, S., Huguet, T., Gentzbittel, L., and Petitprez, M. 2007. Characterization of the interaction between the bacterial wilt pathogen Ralstonia solanacearum and the model legume plant Medicago truncatula. Mol. Plant-Microbe Interact. 20:159-167.

van der Wolf, J. M., Bonants, P. J. M., Smith, J. J., Hagenaar, M., Nijhuis, E. van Beckhoven, J. R. C. M., Saddler, G. S., Trigalet, A., and Feuillade, R. 1998. Genetic diversity of Ralstonia solancaerum race 3 in Western Europe determined by AFLP, RC-PFGE and rep-PCR. Pages 44-49 in: Bacterial Wilt Disease: Molecular and Ecological Aspects. P. Prior, C. Allen, and J. Elphinstone, eds. Springer-Verlag, New York.

Vasse, J. 1995. Microscopic studies of intercellular infection and protoxylem invasion of tomato roots by Pseudomonas solanacearum. Mol. Plant-Microbe Interact. 8:241-251.

Wairuri, C. K., van der Waals, J. E., van Schalkwyk A., and Theron, J. 2012. Ralstonia solanacearum needs Flp pili for virulence on potato. Mol. Plant Microbe Interact. 25:546-556.

Winstead, N. N., and Kelman, A. 1952. Inoculation techniques for evaluating resistance to Pseudomonas solanacearum. Phytopathology 42:628634.

Xue, Q.-Y., Yin, Y.-N., Yang, W., Heuer, H., Prior, P., Guo, J.-H., and Smalla, K. 2011. Genetic diversity of Ralstonia solanacearum strains from China assessed by PCR-based fingerprints to unravel host plantand site-dependent distribution patterns. FEMS (Fed. Eur. Microbiol. Soc.) Microbiol. Ecol. 75:507-519 